\title{
Behavior of prostate cancer cells in a nanohydroxyapatite/collagen bone scaffold
}

\author{
Susana Cruz-Neves, ${ }^{1,2,3}$ Nilza Ribeiro, ${ }^{1,2,3}$ Inês Graça, ${ }^{4,5}$ Carmen Jerónimo, ${ }^{4,6}$ \\ Susana R. Sousa, ${ }^{1,2,7}$ Fernando J. Monteiro ${ }^{1,2,3}$ \\ ${ }^{1}$ i3S — Instituto de Investigação e Inovação em Saúde, Universidade do Porto, Portugal \\ ${ }^{2}$ INEB - Instituto de Engenharia Biomédica, Divisão de Biomateriais, Universidade do Porto, Rua Alfredo Allen, \\ Porto 4200-135, Portugal \\ ${ }^{3}$ Departamento de Engenharia Metalúrgica e de Materiais, Faculdade de Engenharia, Universidade do Porto, Rua Roberto \\ Frias, Porto 4200-465, Portugal \\ ${ }^{4}$ Cancer Biology and Epigenetics Group-Research Center, Portuguese Oncology Institute, Porto, Portugal \\ ${ }^{5}$ Instituto Politécnico do Porto, ESTSP-Escola Superior de Tecnologia da Saúde do Porto, Portugal \\ ${ }^{6}$ Department of Pathology and Molecular Immunology, Institute of Biomedical Sciences Abel Salazar (ICBAS), \\ University of Porto, Portugal \\ ${ }^{7}$ ISEP_Instituto Superior de Engenharia do Porto, Instituto Politécnico do Porto, Rua Dr. António Bernardino de Almeida, \\ 431, Porto 4200-072, Portugal \\ Additional Supporting Information may be found in the online version of this article. \\ Correspondence to: S. R. Sousa; e-mail: ssousa@ineb.up.pt \\ Contract grant sponsor: NanoForBone Project, ON2 QREN (Portugal); contract grant number: NORTE-070202-FEDER-005372 \\ Contract grant sponsor: Projeto Estratégico; COMPETE/FEDER (Portugal); contract grant number: PEst-C/SAU/LA0002/2013
}

\begin{abstract}
Prostate cancer (PCa) is the second leading cause of death among men in Europe and U.S. The metastatic dissemination pattern of $\mathrm{PCa}$ is unique, developing bone metastasis as the only site of progression, consequently with a prognosis very poor. The cancer cells interactions within the surrounding bone environment are critical for tumor growth and progression. Secreted protein, acidic and rich in cysteine (SPARC) is described to be involved in $\mathrm{PCa}$ cells migration and invasion into bone. Three-dimensional (3D) in vitro systems that are able to closely resemble the in vivo microenvironment are recently taking importance in cancer research. Original nanohydroxyapatite/collagen scaffolds were designed to resemble bone microenvironment in order to be applied as substitutes in bone defects and as potential biomaterials to mimic skeletal tumors. In fact, these 3D structures were cytocompatible and able to support osteoblast (MC3T3-E1) colonization and to promote bone ingrowth. Additionally, SPARC adsorption onto the scaffolds affected PC3 and LNCaP PCa cell lines behavior. PC3 cells were found to adapt and colonize the scaffolds, differing from LNCaP where cells underwent morphogenic changes and grew as clusters. Furthermore, for the tested SPARC concentration, SPARC plays a role in retaining LNCaP cells at the latter time points while with PC3 cells no significant differences were observed. This characterization study is required to establish a bone model to provide new insights into the poorly understood PCa mechanisms of metastasis to bone and the generation of improved therapies.
\end{abstract}

Key Words: nanohydroxyapatite/collagen scaffold, tumor 3D model, SPARC, prostate cancer, bone metastasis, MC3T3-E1

\section{INTRODUCTION}

Prostate cancer (PCa) has become the second leading cause of death among men both in Europe and in United States. ${ }^{1}$ Each year, around 220,000 American men are diagnosed with PCa and 29,000 die from this pathology. ${ }^{2}$ Most deaths from PCa are caused by widespread metastasis, in which bone is the preferential site of progression (60-70\%). ${ }^{3}$ Bone metastases are commonly found in the vertebrae, pelvis, ribs, sternum, femur and skull; its complications include pain, increased risk of facture, hypercalcemia, and a decreased blood cell count. The prognosis of cancers that metastasize to bone is in general very poor and the treatment for bone metastases tends to minimize the symptoms by reducing pain and the risk of fracture. ${ }^{4}$ Reciprocal interactions between PCa cells and bone cells result in a selective advantage for tumor growth leading to bone destruction or new bone matrix deposition. ${ }^{5}$ The process of PCa metastasis to bone can be described by the "seed and soil," and/or by the mechanical (or hemodynamic) mechanism theories. ${ }^{6}$

Koeneman et al. proposed that bone is a highly protective and restricted environment inhibiting the growth and survival 
of cancerous cells and in order to thrive in the bone microenvironment, these cells must acquire osteomimetic properties. ${ }^{7}$ Bone extracellular matrix is constituted essentially by hydroxyapatite $(\mathrm{HA})$ crystals $\left[\mathrm{Ca}_{10}\left(\mathrm{PO}_{4}\right) 6(\mathrm{OH})_{2}\right]$, along with collagen (mainly type I), and noncollagenous proteins, such as secreted protein, acidic and rich in cysteine (SPARC). The glycoprotein SPARC belongs to a family of small, calcium and collagen binding proteins. SPARC is synthesized by different cell types, namely osteoblasts, fibroblasts, endothelial cells, vascular smooth muscle cells, and tumor cells. ${ }^{8,9}$ SPARC displays oncogenic properties in many tumor types, highlighting the carcinoma of the prostate. ${ }^{10,11}$ Jacob et al. suggested that specific homing factors present in bone facilitate the growth of PCa cells, in which SPARC may be responsible for chemotaxis of PCa cells to bone. ${ }^{12}$ However, published data on the role of SPARC during tumorigenesis are inconsistent and often conflicting, even among the same tumor types, both in clinical correlative studies and in animal models. It appears that the capacity of SPARC to promote or inhibit tumor progression is dependent on the cell-type, tumor-type and stage, and the specific context of the tumor microenvironment. ${ }^{10,11,13}$ At present, a number of studies involving PCa lines cultured on biomaterials have been published in order to study tumorigenesis in vitro on prostate cancer cells. ${ }^{14-18}$ Yet the development of a new threedimensional (3D) culture model that recreates bone native tumor microenvironment and at the same time has the ability to be easily functionalized with active agents (SPARC) might be a valid strategy to understand the involvement of SPARC in bone metastization.

This work describes the use of an engineered bone biomimetic 3D model to enhance our understanding upon the role of SPARC in PCa bone metastasis. This model helped to explore innate PCa cell behavior in the biomimetic structural and spatial configuration of bone. In addition, by understanding the nature of cellular interactions between $\mathrm{PCa}$ and bone microenvironment, it may be possible to develop novel therapeutic approaches for the prevention and treatment of $\mathrm{PCa}$ bone metastasis, since one of the principles of bone targeting in neoplastic disease is to break the cycle of cancer-bone interactions. ${ }^{19}$

\section{MATERIALS AND METHODS}

\section{Scaffolds preparation}

NanoHA scaffolds. The scaffolds were produced through the already described polyurethane (PU) sponge impregnation method. ${ }^{20}$ The flexible PU sponges (Recticel) were cut into a cylindrical shape using a pneumatic hole punch. The ceramic slurry was prepared using the nanoHA powder (NanoXIM HAp202, Fluidinova, Portugal), ultrapure water and a dispersing agent (Dolapix CE-64, Zschimmer \& Schwarz), in a ratio of 5.6: 4.4: $0.2(\mathrm{w} / \mathrm{v})$, respectively. The samples were submitted to the following heat-treating cycle: heating to $600^{\circ} \mathrm{C}$ at a heating rate of $1^{\circ} \mathrm{C} / \mathrm{min}$, followed by $1 \mathrm{~h}$ plateau at $600^{\circ} \mathrm{C}$; heating from $600^{\circ} \mathrm{C}$ to $830^{\circ} \mathrm{C}$ $\left(4^{\circ} \mathrm{C} / \mathrm{min}\right)$ followed by $1 \mathrm{~h}$ plateau at $830^{\circ} \mathrm{C}$, finally the cycle was completed with natural cooling inside the furnace (Thermolab).
Preparation of the collagen solution. Insoluble type I collagen from bovine Achilles tendon (Sigma-Aldrich, C9879) was swollen in $0.01 M$ hydrochloric acid ( $\mathrm{HCl})$ solution. Using an Ultra-Turrax T25 (IKA, Germany), the dispersion was homogenized for $3 \mathrm{~h}$ at $10,000 \mathrm{rpm}$, the temperature was kept bellow $4^{\circ} \mathrm{C}$. Several collagen concentrations were tested, namely $0.50 \%, 0.25 \%, 0.15 \%$, $0.10 \%$, and $0.05 \%(\mathrm{w} / \mathrm{v})$.

NanoHA/collagen scaffolds. NanoHA scaffolds were immersed in type I collagen solution and taken to a vacuum oven (Binder) for $48 \mathrm{~h}$ at room temperature (RT). As crosslinking agents $7.24 \mathrm{mM}$ of $N$-hydroxysuccinimide (NHS, Fluka, BioChemika) and $14.8 \mathrm{mM}$ of $N$-(3-dimethylaminopropyl)- $N$ '-ethylcarbodiimide hydrochloride (EDC, Fluka, BioChemika) were used. The crosslinking was performed in 2-morpholinoethane sulfonic acid (MES buffer, 0.05M, Sigma), to minimize the hydrolysis of EDC. $.^{21,22} \mathrm{NanoHA} / \mathrm{col}-$ lagen scaffolds were immersed in the freshly prepared crosslinking solution for $2 \mathrm{~h}$ at $4^{\circ} \mathrm{C}$. Afterwards, the scaffolds were washed three times with MES buffer.

\section{Scaffolds characterization}

Scanning electron microscopy (SEM). The SEM/EDS analysis was performed using a High resolution (Schottky) Scanning Electron Microscope with X-Ray Microanalysis and Electron Backscattered Diffraction analysis (Quanta 400 FEG ESEM/EDAX Genesis X4M). Scaffolds were mounted in SEM sample holders using epoxy glue (Araldite). Samples were coated with a gold/palladium (Au/Pd) thin film obtained by 90 to 110 s exposure, by sputtering, using the SPI Module Sputter Coater equipment.

Attenuated total reflectance-Fourier transform infrared (ATR-FTIR). ATR-FTIR was carried out using a Perkin Elmer 2000 FTIR/RAMAN spectrometer (Wellesley). The samples were mounted on an ATR accessory named Split Pea (Harrick Scientific Corporation) supplied with a silicon hemispherical crystal. The analyzed samples were the scaffolds (nanoHA and nanoHA/collagen), the crosslinked collagen fibers, as well as the sintered nanoHA powder. Chemical characterization was done at a spectral resolution of $4 \mathrm{~cm}^{-1}$ on a frequency region of 400 to $4000 \mathrm{~cm}^{-1}$ and 100 scans were accumulated per sample.

Microcomputed tomography (micro-CT). The samples were further characterized by micro-CT analysis using a SKYSCAN 1072 (Skyscan, Kontich, Belgium) equipment. The scaffolds were scanned in high-resolution mode of $6.69 \mu \mathrm{m}$ $x / y / z$, where the ROI (region of interest) analyzed was 300 slices, which corresponds to approximately $2 \mathrm{~mm}$ height. The scanner operated at $57 \mathrm{kV}$ and a tube current of 175 $\mu \mathrm{A}$. The scanned specimen's representative data was converted into binary images using a lower and upper gray threshold of 70 and 255 respectively (70 to determine the porosity and 255 to identify the apatite content along the scaffold, therefore distinguishing material from pore voids). The described operating parameters were kept constant for 
all the samples. The sliced 2D tomographic raw images were processed using CT Analyzer v.1.12.0.0 (SkyScan) and 3D virtual models of the scaffolds were created using (CTVox, SkyScan).

SPARC quantification by radioactivity. A ${ }^{125}$ I radiolabelling assay was performed to quantify the SPARC $\left({ }^{125}\right.$ I-SPARC) adsorbed on nanoHA/collagen samples. To perform this experiment, porous granules of nanoHA/collagen $(20 \mathrm{mg}$ per replica) were obtained from nanoHA/collagen scaffolds, by carefully crushing and sieving the scaffolds (sizes of granules obtained from $1.18 \mathrm{~mm}$ to $1.70 \mathrm{~mm}$ ).

The SPARC used is from human source (Sigma, SRP3159) used at a concentration of $10 \mu \mathrm{g} / \mathrm{mL}$ (which is the concentration of the SPARC solution used in cell culture later on). The quantification of SPARC adsorbed on granules of nanoHA/collagen was accomplished with ${ }^{125}$ I labeled SPARC $\left({ }^{125}\right.$ I-SPARC) using the Iodogen method, and purified using a Sephadex G-25 column (PD-10 column, Amersham Biosciences), to remove unbound ${ }^{125} \mathrm{I}^{23,24}$ Previous to the protein adsorption assays the granules were equilibrated overnight at RT, in degased PBS with $0.01 \mathrm{M} \mathrm{NaI}$ (PBSI) to prevent adsorption of free ${ }^{125} \mathrm{I}$ ions present in trace amounts in ${ }^{125}$ I-SPARC. The contribution of free ${ }^{125} \mathrm{I}$ to the total radioactivity found on the scaffolds surfaces was estimated using unlabeled SPARC solutions (with a final concentration of $10 \mu \mathrm{g} / \mathrm{mL}$ ) and an amount of free ${ }^{125}$ I ion equivalent to that present as ${ }^{125} \mathrm{I}$ ion in the labeled protein solutions.

For the adsorption experiments, the SPARC solution was prepared adding ${ }^{125}$ I-SPARC to unlabelled SPARC to obtain solutions with a desired final activity of about $10^{6} \mathrm{cpm} / \mathrm{mL}$. The nanoHA/collagen granules were incubated in a ${ }^{125}$ I-SPARC solution during $60 \mathrm{~min}$ at $25^{\circ} \mathrm{C}$. To assess the influence of the rinsing procedure the gamma countings of the samples were measured before and after the granules were rinsed $3 \times$ in phosphate buffered saline (PBS, Sigma, $\mathrm{pH}=7.4)(500 \mu \mathrm{L})$. At the end of the immersion time in PBS $(48 \mathrm{~h})$ the samples were rinsed $3 \times$ with PBS, and then transferred to radioimmunoassay tubes (RIA) with $500 \mu \mathrm{L}$ of PBS and surface activity was measured using a gamma counter (Wallac Wizard, model 1470). The rinsing procedure was performed in order to remove both free iodine and non-adsorbed protein.

The counts were averaged, and the surface concentration was calculated by the following Eq. (1):

$$
\operatorname{SPARC}\left(\mu \mathrm{g} / \mathrm{m}^{2}\right)=\frac{\text { Counts }(\mathrm{cpm}) \times|\operatorname{SPARC}|_{\text {solution }}(\mu \mathrm{g} / \mathrm{mL})}{\operatorname{SPARC}_{\text {solution }}(\mathrm{cpm} / \mathrm{mL}) \times \operatorname{SA}\left(\mathrm{m}^{2}\right)}
$$

where the counts represent the gamma activity of the samples, SPARC $_{\text {solution }}$ is the specific gamma activity of the SPARC solution expressed in counts per $\mathrm{mL}$ of solution, |SPARC| is the concentration of SPARC solution and SA stands for the actual surface area of the granules, which was determined by micro-CT. ${ }^{23,25}$

\section{In vitro biological studies}

The MC3T3-E1 cells are derived from a pre-osteoblastic cell line from normal mouse calvaria. The PC3 cells (androgen independent) are derived from a human PCa bone metastasis, whereas LNCaP cells (androgen sensitive) are derived from a human PCa lymph node metastasis (American Type Tissue Collection, ATCC), kindly provided by Portuguese Oncology Institute, Porto, Portugal.

Maintenance of MC3T3-E1, PC3, and LNCaP cell lines. MC3T3-E1 cells were grown in $\alpha$-minimum essential medium ( $\alpha$-MEM, Gibco), supplemented with 10\% fetal bovine serum [(FBS), Invitrogen] and $1 \%$ penicillin/ streptomycin [(P/S) (Gibco)]. The PC3 and LNCaP cell lines were maintained in 50\% RPMI 1640 and 50\% Ham's F-12 Nutrient Mix (v/v) (Gibco, Invitrogen) and in RPMI 1640, respectively. Both media were supplemented with $10 \%$ (v/v) FBS Heat inactivated (Gibco, Invitrogen) and 1\% P/S. Cells were incubated in a humidified incubator $\left(37^{\circ} \mathrm{C}\right.$ and $5 \% \mathrm{CO}_{2}$ ). The culture medium was replaced three times a week.

Cell cultures and SPARC adsorption on the scaffolds. To perform the in vitro biological studies the scaffolds were sterilized by immersion in a $70 \%$ ethanol solution $(\mathrm{v} / \mathrm{v})$ for $4 \mathrm{~h}$, and incubated with the corresponding medium (not supplemented) overnight. The porous structures were incubated with the SPARC solution $(10 \mu \mathrm{g} / \mathrm{mL})$ during $60 \mathrm{~min}$ at RT. Subsequently cells were seeded on the structures in commercial 96-well cell culture plates, at a cell seeding density of $1 \times 10^{5}$ cells/well for MC3T3-E1 and PC3, and 6.5 $\times 10^{5}$ cells/well for LNCaP. The medium was changed three times a week. For each material and cell line, six replicates were established for the resazurin assay. Control cultures were done on tissue culture polystyrene (TCPS) undergoing the same conditions as the scaffolds.

Metabolic activity. For this assay, $10 \%(\mathrm{v} / \mathrm{v})$ of fluorescent dye (R7017, Sigma) was added to the cell medium, including controls, and incubated at $37^{\circ} \mathrm{C}$ in a humidified atmosphere of $5 \% \mathrm{CO}_{2}$ for $4 \mathrm{~h}$. Then $100 \mu \mathrm{L}$ of the solution were collected and transferred into a black 96-well plate and fluorescence intensity was measured by a fluorescence reader (SynergyMx, BioTek) using Gen5 1.09 software at $\lambda=530$ and $\lambda=590 \mathrm{~nm}$ for excitation and emission, respectively.

Statistical analysis. The experimental results were statistically analyzed by one-way ANOVA, followed by post hoc Tukey test using Statistical Package for Social Sciences (SPSS) version 21 (IBM). The values were considered statistically significant when $p<0.05$.

Confocal laser scanning microscopy (CLSM). Cell-seeded samples were fixed with 4\% paraformaldehyde (PFA) for 15 min. Cells were therefore permeabilized with $0.1 \%$ Triton $\mathrm{X}-100$ and incubated in $1 \%$ bovine serum albumin (BSA) for $30 \mathrm{~min}$ at $37^{\circ} \mathrm{C}$. The cytoskeletal F-actin filaments of the cell were stained with Alexa Fluor 594 Phalloidin 


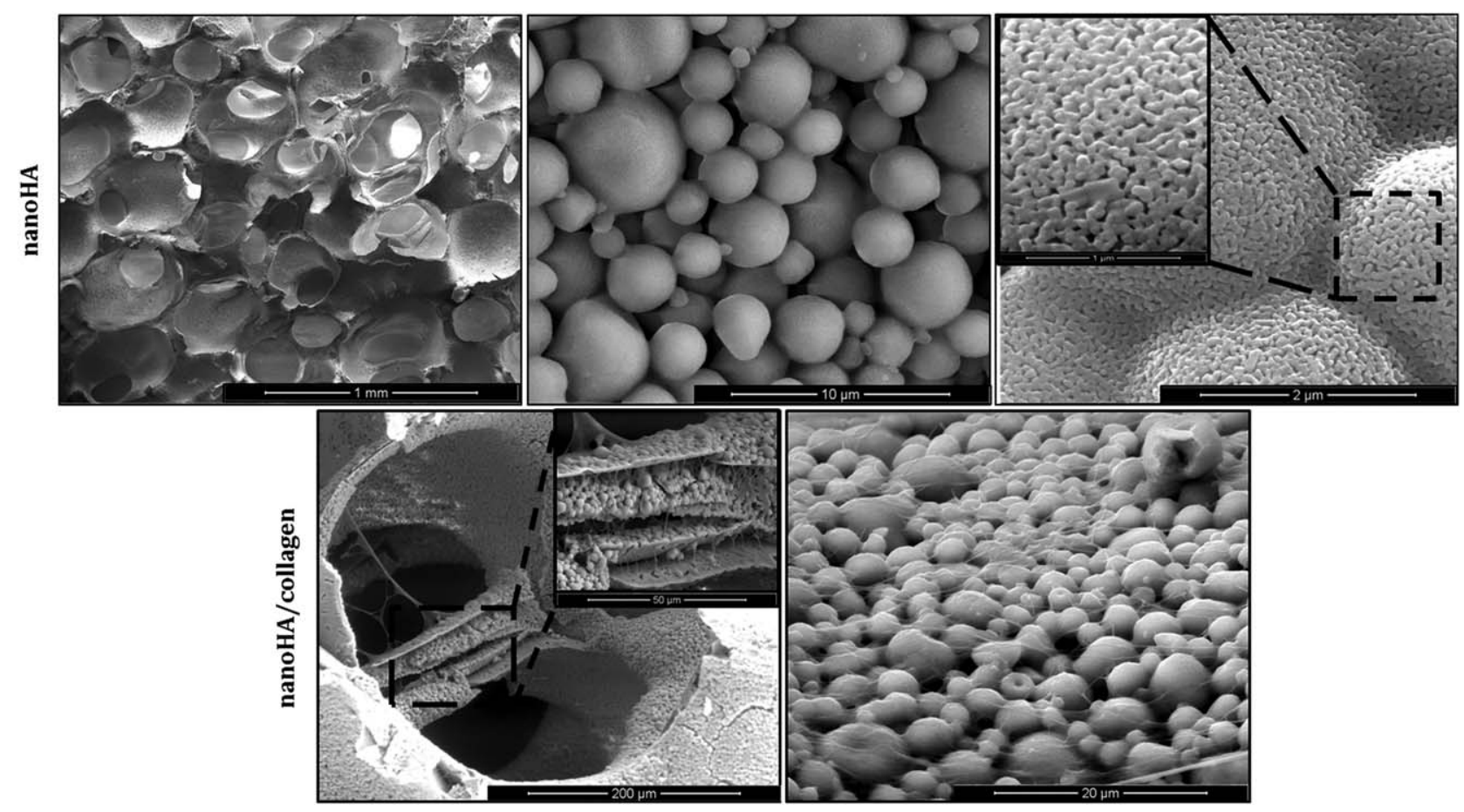

FIGURE 1. SEM images of porous scaffolds obtained by the PU impregnation method. In the top left image it may be observed macropores and pore interconnectivity. In the top middle image, the spherical aggregates morphology present in the nanoHA powder were preserved during the sintering cycle and the aggregates were bond through small contact areas. In the top right image is perceptible the nano-sized porosity and its magnification. The SEM images (down) taken in several areas of nanoHA scaffolds with $0.05 \%$ collagen crosslinked with EDC/NHS.

(1:100, Molecular Probes A12381, Invitrogen) in 1\% BSA during $30 \mathrm{~min}$ in the dark at RT. The nuclei of cells were counterstained with Hoechst 33342 (H1399, Life Tech) in PBS during $15 \mathrm{~min}$ in the dark at RT. The scaffolds were mounted in a proper dish (Ø $35 \mathrm{~mm}$ ). Images were acquired by using a Leica SP5 Confocal microscope with $20 \times$ oil objective, and processed with Leica Application Suite Version 2.6.0.

SEM analysis of cell-seeded scaffolds. Cells were fixed using a solution of $1.5 \%$ gluteraldehyde (v/v) (Agar) in $0.14 M$ sodium cacodylate buffer (Merck) for $30 \mathrm{~min}$ at RT. Afterwards the samples were dehydrated by immersion in a serial of graded ethanol solutions for $10 \mathrm{~min}$ in each. The final step consisted in adding hexamethyldisilazane (Sigma) to each well and let the scaffolds dry. The samples were mounted likewise as in Scanning electron microscopy (SEM) section.

\section{RESULTS}

Physical, morphological, and chemical characterization of the porous scaffolds

Using the PU sponge impregnation method it was possible to produce highly porous hydroxyapatite scaffolds in a cylindrical shape with $2.34 \pm 0.29 \mathrm{~mm}$ height and $5.33 \pm$ $0.19 \mathrm{~mm}$ of diameter.

Scanning electron microscopy (SEM). The nanoHA powder used to produce the macroporous scaffolds was originally in the form of nanoparticles aggregates with a spherical morphology, which was preserved during the sintering cycle, as depicted in Figure 1. These structures presented macropore diameters of approximately $326.23 \pm 78.10 \mu \mathrm{m}$, micropores and nanopores with dimensions around $46.50 \pm 6.67 \mathrm{~nm}$ were found at higher magnifications. The preparation of the nanoHA/collagen scaffolds involved the evaluation of the most suitable collagen concentration. Therefore, Therefore, the lowest collagen concentration of $0.05 \%$ was more adequate due to the formation of collagen fibers without fully covering the nanoHA surface as it happened with the other collagen concentrations used $(0.50 \%, 0.25 \%, 0.15 \%$ and $0.10 \%)$. Additionally, it may be observed in Figure 1 that the distribution of the $0.05 \%$ collagen fibers was heterogeneous. Nonetheless the collagen fibers, as well as the nanoHA surface, are both well exposed for cell-surface interactions as in bone.

Attenuated total reflectance-Fourier transform infrared (ATR-FTIR). The ATR-FTIR spectra for all the samples containing nanoHA are represented in Figure 2. The bands appearing at 630 and $3572 \mathrm{~cm}^{-1}$ were due to the vibrational and stretching mode of hydroxyl ions $\left(\mathrm{OH}^{-}\right)$during the sintering cycle. The well-defined peaks at 564 and $600 \mathrm{~cm}^{-1}$ were attributed to the bending vibration of $\mathrm{PO}_{4}^{3-}$. The characteristics bands of carbonate ions (present at 882, 1421, and $1460 \mathrm{~cm}^{-1}$ ) have not been detected. This suggests that no carbonate substitution in nanoHA particles occurred after being exposed to high temperature during the sintering cycle. ${ }^{26}$

The main bands of the collagen fingerprint at 1661 to $1640 \mathrm{~cm}^{-1}$ are attributed to amide I (carbonyl stretching $\mathrm{C}=0$ ), at $1549 \mathrm{~cm}^{-1}$ is associated to amide II (due to the vibrations in the plane of $\mathrm{C}-\mathrm{N}$ stretching and $\mathrm{N}-\mathrm{H}$ bending), and at 


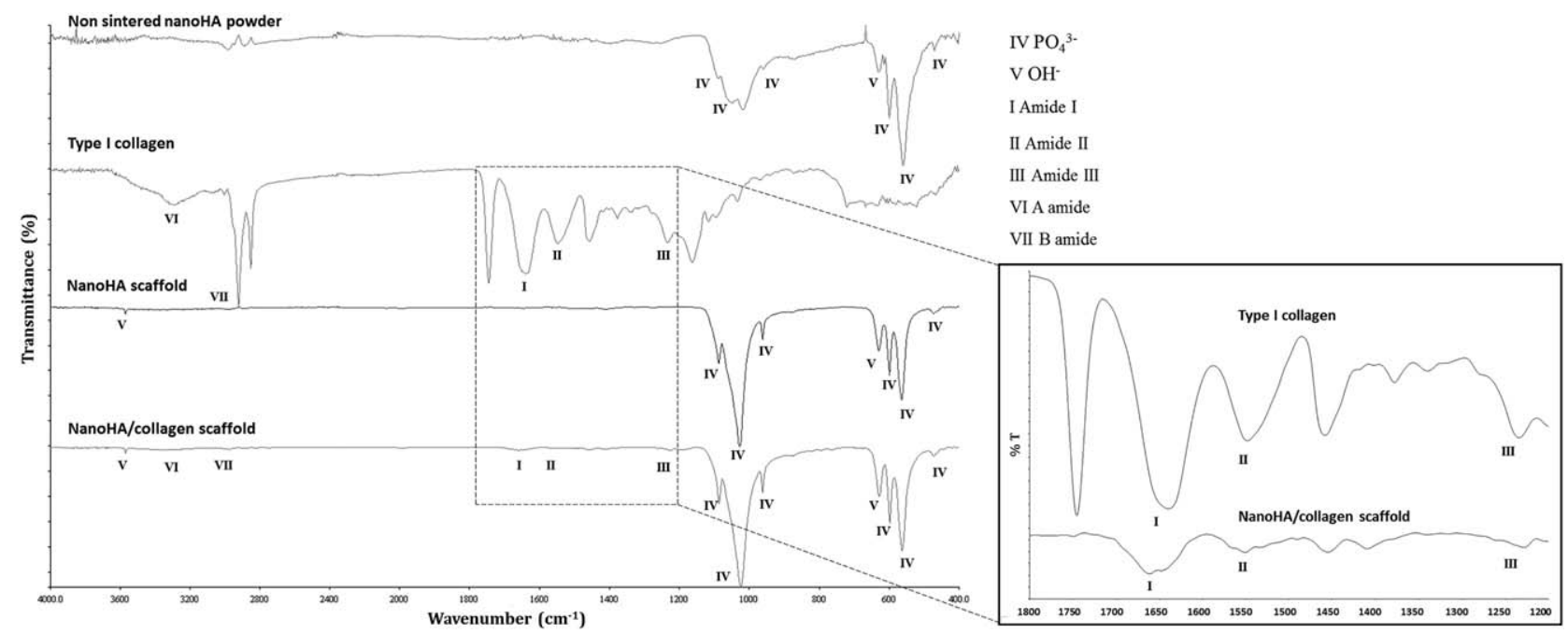

FIGURE 2. ATR-FTIR spectra of nonsintered nanoHA powder, crosslinked collagen fibers, nanoHA scaffold, and nanoHA/collagen scaffold. The characteristic peaks of nanoHA and collagen are present. ATR-FTIR spectra magnification of collagen and nanoHA/collagen scaffold samples between the wavenumber 1800 to $1200 \mathrm{~cm}^{-1}$

1234 to $1228 \mathrm{~cm}^{-1}$, the band corresponds to the vibrations in the plane of amide III (C-N stretching and N-H bending). ${ }^{27}$

Micro-CT. Further morphological analysis of the nanoHA macroporous scaffolds was performed using micro-CT, in which 3D representations and micro-CT video were obtained (Supporting Information Figure S1 and micro-CT video of the Supporting Information). The mean macroporosity obtained was $62.40 \pm 1.76 \%$, the respective mean pore size was $367.02 \pm 5.79 \mu \mathrm{m}$, and the actual surface area was $193 \pm 2 \mathrm{~mm}^{2}$. Micro-CT analysis provided more accurate information on the scaffolds, sustaining the SEM results and confirming that these structures have adequate structural properties, such as pore size and pore interconnectivity present along the scaffold.

SPARC adsorption on scaffolds. SPARC adsorption on scaffolds was evaluated by radiolabeling. Residual free ${ }^{125} \mathrm{I}$ adsorption to the scaffolds surface was found to be about $0.2 \%$, after exposure of this surface to mixtures with different concentrations of unlabeled SPARC plus labeled free iodide. This amount is negligible considering that in our solution we only have ca. $2 \%$ free iodide ion, instead of $100 \%$.

The amount of SPARC adsorbed on scaffolds surface was $0.47 \pm 0.10 \mu \mathrm{g} / \mathrm{m}^{2}$ (actual surface area obtained by micro-CT).

\section{In vitro assays}

MC3T3-E1 cell line behavior within the scaffolds. Figure $3(\mathrm{~A}, \mathrm{~B})$ represents the cell metabolic activity of MC3T3-E1 cells when cultured in nanoHA and nanoHA/collagen scaffolds during 21 days.

The cells present on both scaffolds had an increasing metabolic activity over time indicating that these constructs displayed a non-cytotoxic effect and had the ability to support osteoblast cell adhesion. The normalized results in graph $\mathrm{B}$ provided a better perception of the behavior of cells in the 3D environment. When comparing $4 \mathrm{~h}$ with 21 days, in Figure 3(B), the values for nanoHA increased fourfold while in nanoHA/collagen increased 3.8-fold.

During the observations of MC3T3-E1 cell distribution and morphology by CLSM, cells were distributed throughout the scaffolds and were found at different depths, Figure 4. At $24 \mathrm{~h}$ cells already adopted an osteoblast-like morphology. The images from 14 days (data not shown) were identical to the ones from 21 days. Undoubtedly, cells proliferated over the scaffolds surface, and formed continuous cell layers contouring the pore walls.

SEM imaging analysis revealed that osteoblasts were able to attach and spread on the surface of both nanoHA and nanoHA/collagen constructs, Figure 5. At $24 \mathrm{~h}$ of cell culture, cells exhibit a typical well-spread and spindle-like morphology and closely bind to the surface through cytoplasmic extensions away from the cell main body. After 14 days of culture, both types of 3D surfaces were highly covered by cells and at higher magnifications, a fibrillar ECM produced from cells was observed, while cellular secreted products, such as natural apatite, could be identified mainly at 21 days (black circle). At the later time points, it became difficult to individually identify cells due to their higher number, cell-cell contact and partial overlapping. Herein, cells presented predominantly a flatter morphology.

\section{PCa cells}

PC-3 and LNCaP metabolic activity. PC3 cells were seeded on the nanoHA and nanoHA/collagen scaffolds with and without the adsorbed SPARC. The metabolic activity of PC-3 cells cultured on TCPS increased considerably with time, while cell seeded in scaffolds presented a sustained increase, Figure $6(A)$. The presence of collagen in unmodified scaffolds or grafted with SPARC induced an increase of cell metabolic activity at 1, 2, 4, and 7 days of cell culture.

The cell metabolic activity of LNCaP cells grown in bone-like constructs clearly decreased along the 21 days, 
(A)

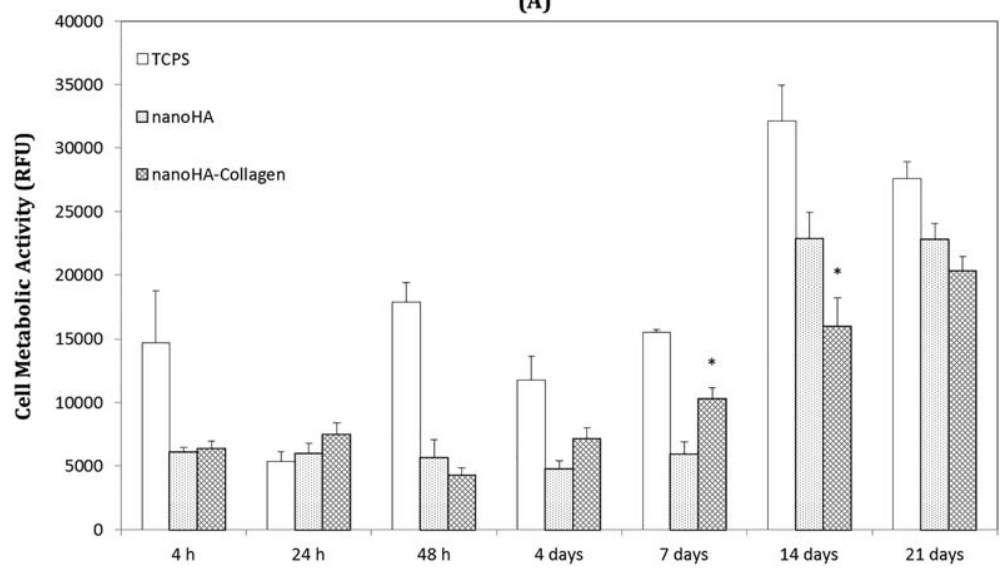

(B)

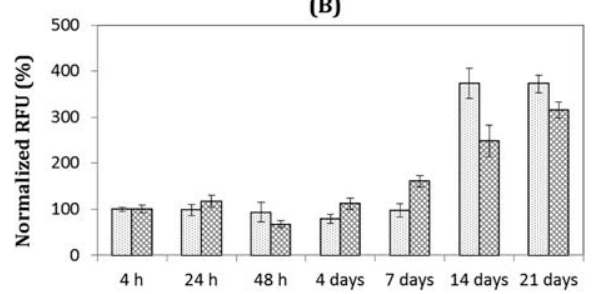

FIGURE 3. Metabolic activity of MC3T3-E1 cultured on TCPS, nanoHA, and nanoHA/collagen scaffolds during 21 days, estimated by Alamar Blue assay. (A) Metabolic activity of MC3T3-E1 expressed in RFU and (B) normalized RFU (\%). *Significant difference from nanoHA within the respective time point $(p<0.05)$.

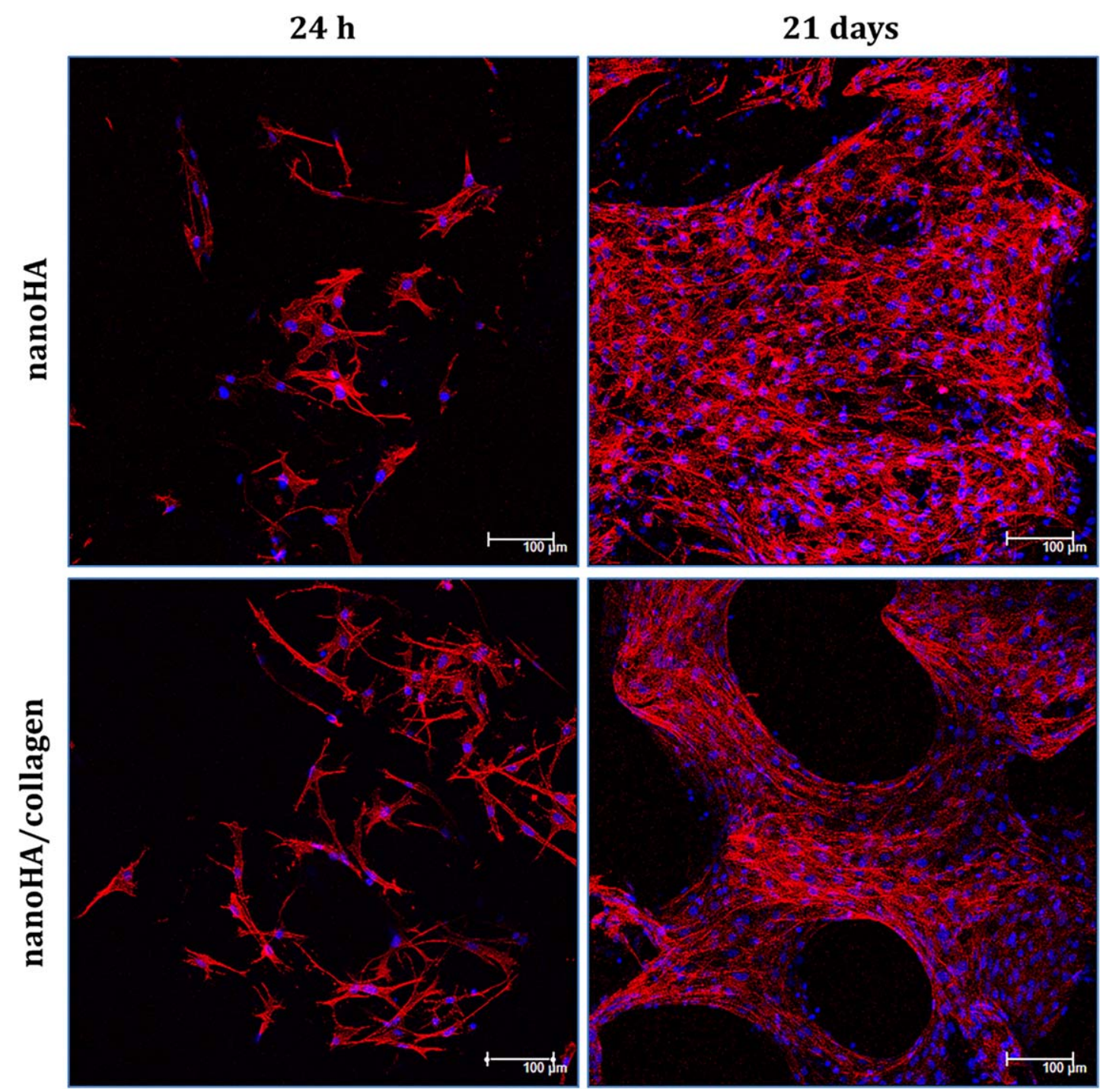

FIGURE 4. CLSM fluorescence images of the cell distribution and morphology of MC3T3-E1 in the 3D scaffolds during 21 days of culture. The cell cytoskeleton is stained in red (Phalloidin 594) and the nucleus in blue (Hoechst). Scale bar: $100 \mu \mathrm{m}$. 
24 h
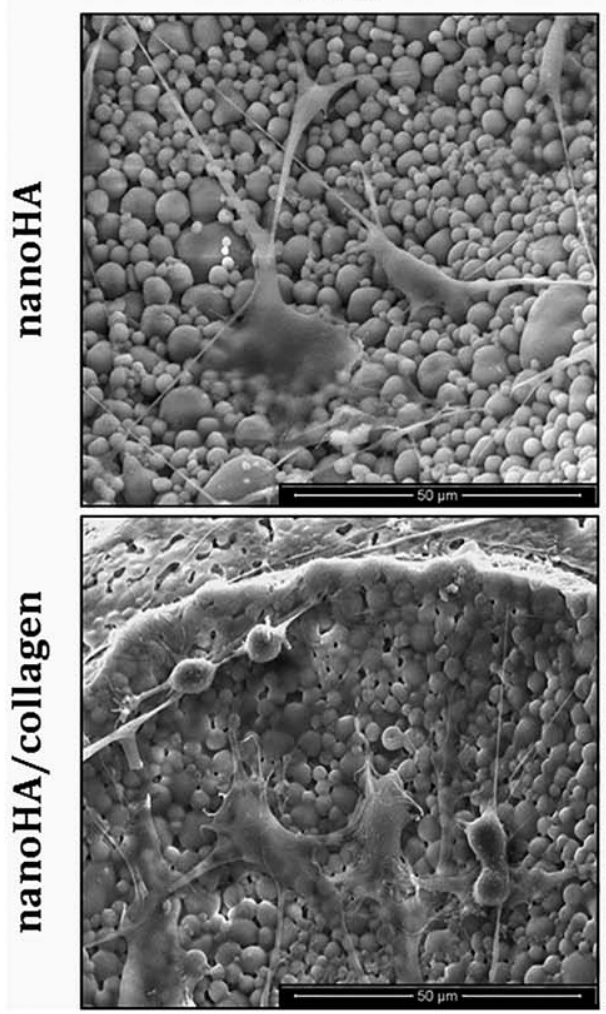

14 days

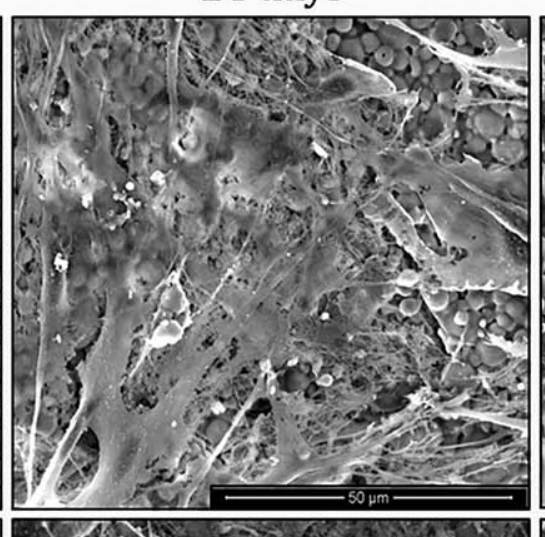

21 days

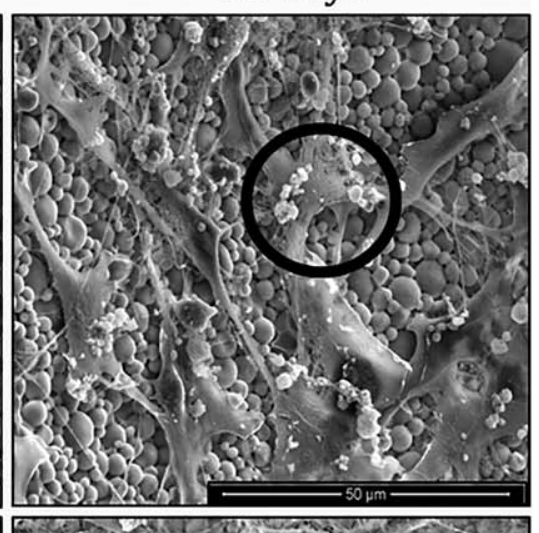

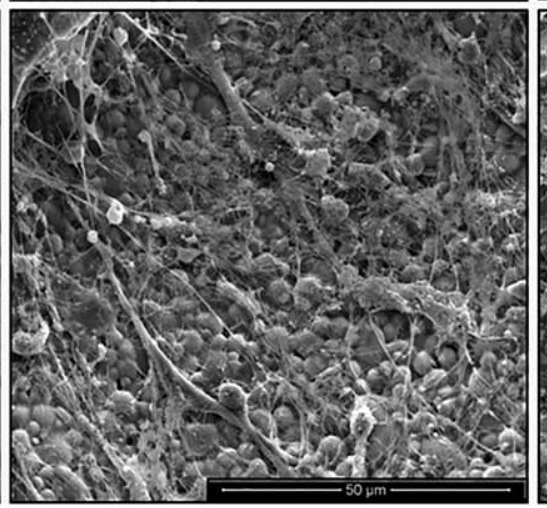

FIGURE 5. SEM micrographs of cell adhesion and morphology of MC3T3-E1 cells at 14 and 21 days, on nanoHA and nanoHA/collagen scaffolds. At 14 days fibrillar ECM produced by cells can be observed, and the black circle at 21 days identify deposits of natural apatite produced by cells (black circle).

except for the TCPS as seen in Figure 6(A). These differences to TCPS are most probably due to the structural difference between our 3D matrices and the 2D surface of TCPS onto which cell metabolic activity occurs very intensively but far from the actual situation in most scaffolds. ${ }^{18,28,29}$

Other authors have shown behavior of PC3 and LNCaP cells on decelularized ECM similar to that on TCP but only in $2 \mathrm{D}$ conditions. ${ }^{30}$ In order to better distinguish differences between metabolic activity of PCa cells on several scaffolds, a normalization of data was performed relatively to TCPS. No statistical differences were found on PC-3 metabolic activity data when exogeneous SPARC was adsorbed on biocomposites surfaces [Fig. 6(B)].

As far as LNCaP cells are concerned, the metabolic activity on the scaffolds without the immobilized SPARC nearly decreased $100 \%$ whereas on the ones functionalized with SPARC the decrease was around $70 \%$, as seen in Figure 6(B). It can be assumed that LNCaP cells were not able to normally adhere and colonize the scaffolds, but the presence of SPARC counteracted this behavior.

PC-3 and LNCaP behavior and morphology within the scaffolds. Regarding CLSM images analysis (Fig. 7), PC-3 cells seeded in the scaffolds at $24 \mathrm{~h}$ adopted both spherical (whether, trying to adapt to the new 3D environment or undergoing cell division) and spindle-like morphology. Furthermore, the cytoskeleton of these cells was more elongated than on 2D structures, probably due to the presence of many 3D anchoring points at micro and nanopores of the scaffolds. Indeed, PC-3 cells presented filopodia-like extensions to probe the surrounding microenvironment as shown in SEM micrograph (Fig. 8). At day 21, extensive PC-3 cell proliferation could be observed in the CLSM images (Fig. 7). Cells were found at different depths and homogeneously distributed throughout the scaffolds, displaying delineated and elongated actin filaments along the macropores walls, similarly to an osteoblastic-like morphology. By SEM images, two cell morphologies were observed on both scaffolds, on one hand most of the cells displayed a spindle-like morphology and were completely spread. On the other hand, some round cells were also found near to elongated cells, some of them starting to spread with short filopodia. This suggests that spherical cells were in the process of division, where actin filaments networks were contracted, therefore acquiring a round shape. Some fibrillar ECM was identified on the nanoHA/collagen scaffolds at 21 days.

LNCaP cells cultured on 2D structures appeared in a well spread out morphology, while in 3D cultures, cells adopted a round morphology, and formed various cell agglomerate colonies (Fig. 7). The SEM micrographs of the LNCaP seeded scaffolds were helpful to observe that cells adopted cobblestone morphology. After 21 days of culture, LNCaP cells assembled in cell clusters merged into highly compact multilayered masses of cells. Some adherent cells 
(A)
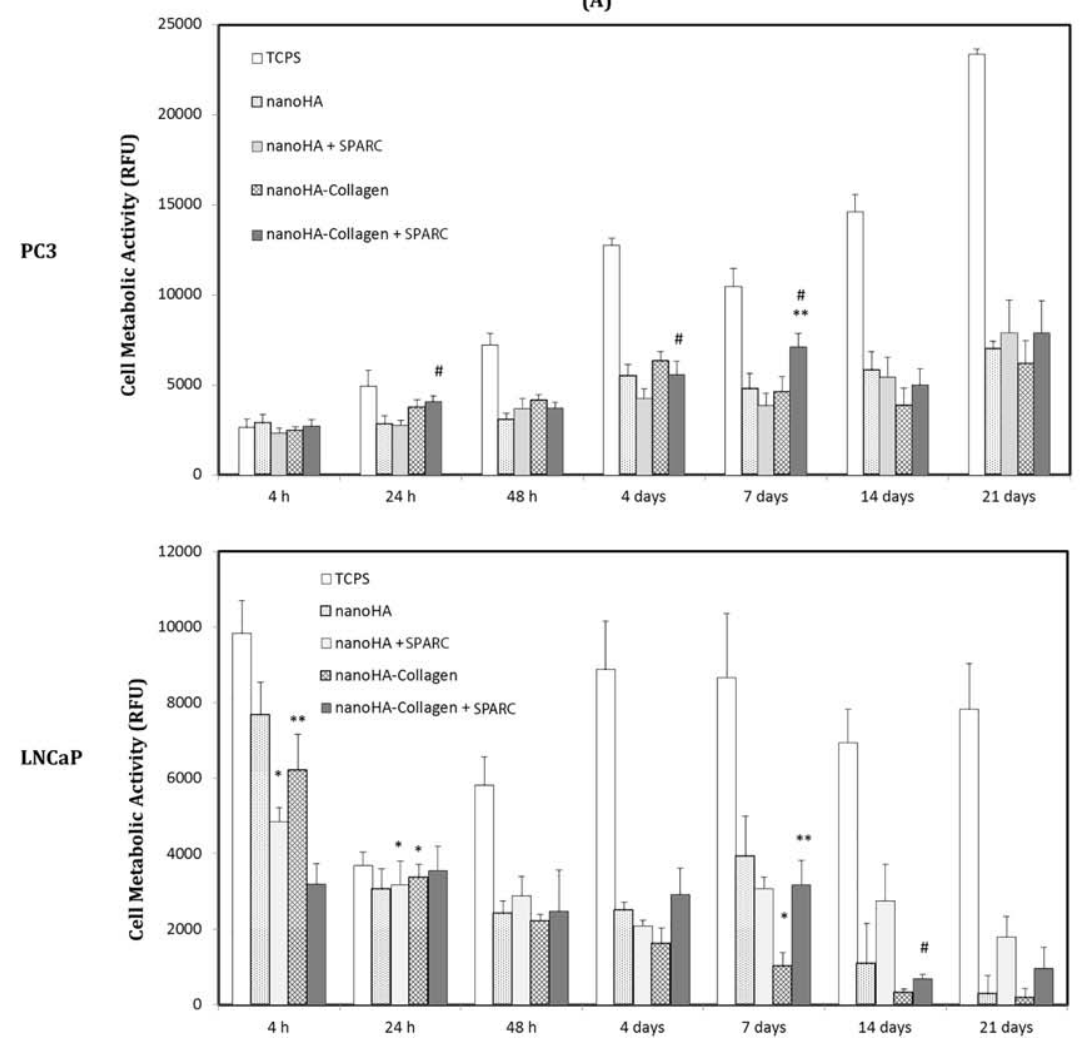

(B)

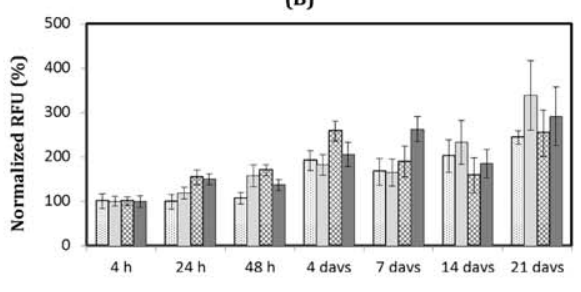

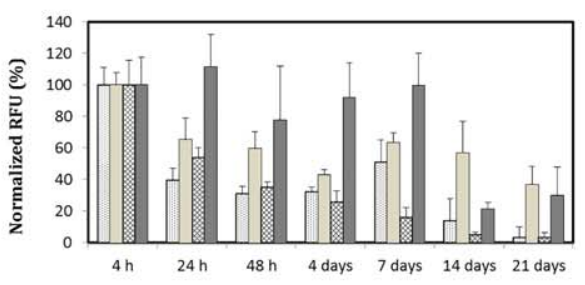

FIGURE 6. Metabolic activity of PC3 and LNCaP cells cultured in TCPS, nanoHA with and without the SPARC and in nanoHA/collagen scaffolds with and without SPARC during 21 days, estimated by Alamar Blue assay. (A) Metabolic activity of PC3 and LNCaP expressed in RFU, and (B) normalized RFU (\%) of PC3 and LNCaP. \#Significant difference from nanoHA + SPARC within the respective time point. **Significant difference from nanoHA/collagen within the respective time point. ${ }^{*}$ Significant difference from nanoHA within the respective time point $(p<0.05)$.

were spotted but the great majority was distributed throughout the scaffolds in spherical aggregates.

SEM and CLSM images corroborates the metabolic activity values found for the LNCaP cell line, where it can be observed that in the scaffolds LNCaP cells show a completely different behavior from the 2D cultures.

\section{DISCUSSION}

The PU sponge impregnation method was useful in the production of highly porous nanoHA scaffolds. In the slurry preparation, the Dolapix CE-64 (dispersing agent) provided a uniform particle size distribution, preventing the overaggregation of HA particles and influencing the sintering quality. It was possible to visualize by SEM that the use of Dolapix CE-64 improved the scaffold density, where a balance between density and adequate porosity was achieved. Porosity ranging from macro to nano scales was present throughout the scaffolds as observed in Figure 1.

To closely resemble the native bone composition, type I collagen was adsorbed onto the nanoHA scaffolds. The collagen concentration of $0.05 \%$ appeared to be the most appropriate to have both biomaterials available to interact with cells or with other molecules, like proteins. To improve the resistance toward enzymatic degradation and to decrease the antigenicity collagen was crosslinked using EDC/NHS (a noncytotoxic and biocompatible crosslinking agent). ${ }^{21,31-33}$
The samples subjected to ATR-FTIR studies confirmed the purity of the nanoHA scaffold, due to the absence of carbonated groups. ${ }^{26}$ Accordingly, the sintering process did not modify the nanophased HA powder composition and the characteristic amide bands of type I collagen were also present on nanoHA/collagen scaffolds.

Pore interconnectivity makes accessible the passageway of cells and fluids, in order to ensure cell survival. When poor molecular diffusion occurs, cells tend to preferentially exhibit peripheral cellular growth, while in the inner part of the scaffold cells undergo apoptosis. ${ }^{34}$ The key parameters such as high and interconnected porosity, pore size, adequate topography, and high surface area to volume ratio are essential to generate uniform cell delivery, assist cellular adhesion, and neo-tissue formation. ${ }^{35,36}$ The produced bioceramic scaffolds have a $62 \pm 2 \%$ macroporosity, fitting within the acceptable porosity range between 45 and $90 \%$, to successfully induced bone growth. ${ }^{25,37}$ Additionally, the mean pore size of $367 \pm 6 \mu \mathrm{m}$ obtained was also adequate, since reported studies identified the pore size ranging between 200 and $500 \mu \mathrm{m}$ as most adequate for osteoblast colonization and new bone matrix deposition. ${ }^{38,39}$ The macropore measurements made by SEM were correlated with the results obtained from the quantitative micro-CT measurements. Other advantageous features were the spherical topography and the microporosity obtained, providing anchoring points for cell adhesion. 
PC3

24 h
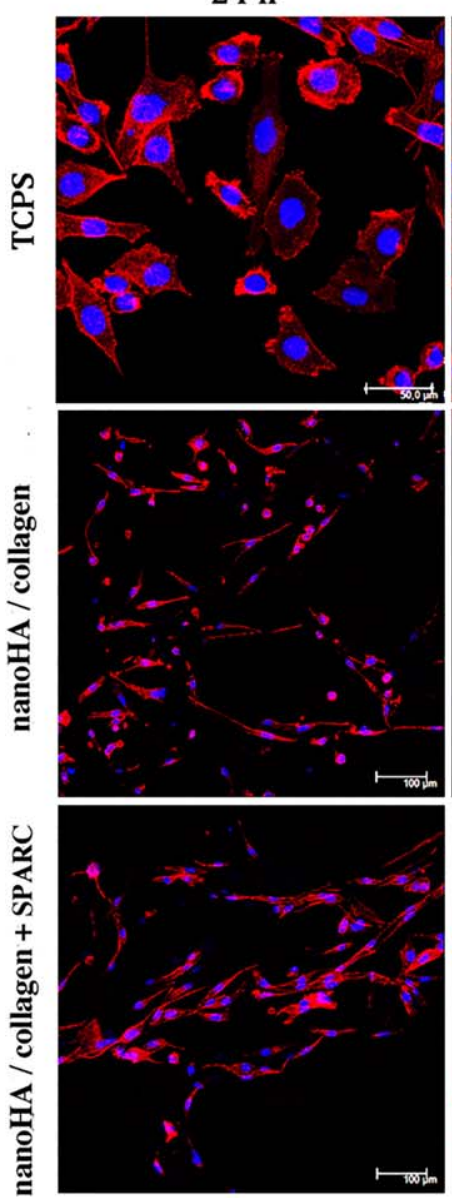

21 days
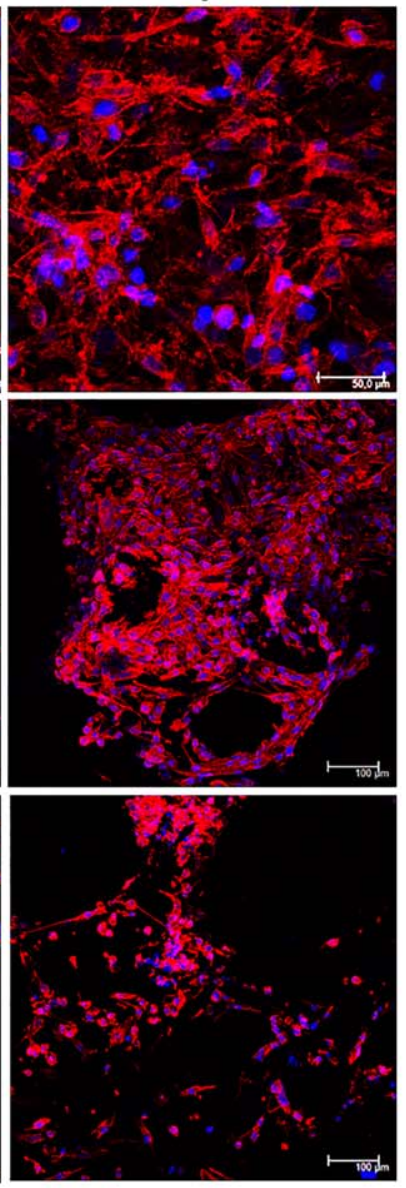

LNCaP

$24 \mathrm{~h}$
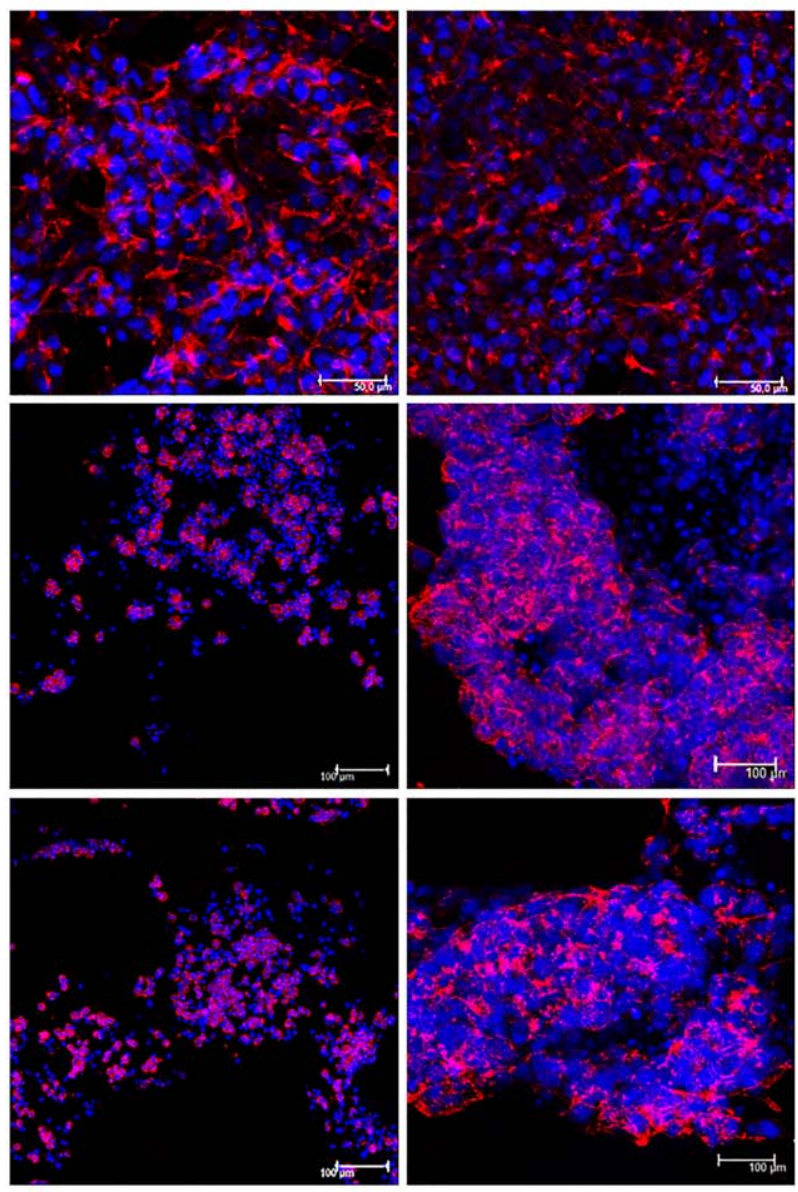

FIGURE 7. CLSM fluorescence images of the cell distribution and morphology of PC3 and LNCaP cells, on the TCPS (2D) and on the 3D nanoHA/ collagen scaffolds at $24 \mathrm{~h}$ and 21 days of culture. The cytoskeleton of cells is stained in red (Phalloidin 594) and the nucleus in blue (Hoechst). Scale bar: $50 \mu \mathrm{m}$ (in 2D) and $100 \mu \mathrm{m}$ (in 3D).

Currently, several attempts are being made to developing methods of modifying the surfaces of biomaterials to achieve the desired biologic responses since substrate physicochemical proprieties influence protein adsorption and its functional activity. ${ }^{14,40,41}$

SPARC, as a counter-adhesive protein, have multiple coordinated functions on cell adhesion, motility, and proliferation during bone mineralization and also in cancer development and progression. The expression and activity of SPARC is correlated with metastatic dissemination ability of PCa cells into bone. ${ }^{12}$ In fact, the study of such protein on a 3D bone-like model could improve the knowledge of cancer related bone metastasis. It is already known that SPARC has a strong affinity toward collagen and hydroxyapatite, thus leading binding to scaffolds such as those present in this study.

The amount of adsorbed SPARC on nanoHA/collagen scaffold surfaces, using radiollabeling ${ }^{125}$ I-SPARC, was 0.470 $\mu \mathrm{g} / \mathrm{m}^{2}$, higher than the one obtained in a previous work, where SPARC was adsorbed on nanophased hydroxyapatite discs $\left(0.190 \mu \mathrm{g} / \mathrm{m}^{2}\right)$ due to the higher surface area exposed with multiple binding points. ${ }^{25}$
The scaffolds induced cell growth and proliferation of MC3T3-E1 cells. Furthermore, these osteoblasts were able to produce ECM after 14 days of culture and deposits of natural apatite secreted by cells were detected mainly at 21 days (Fig. 5).

Two different PCa cell lines (PC3 and LNCaP) were also cultured in the nanoHA/collagen bone-like scaffolds. The PC3 behavior was similar to MC3T3-E1 but the colonization response was lower. PC3 seemed to acquire an "osteoblastlike" morphology, and this behavior is reported to be normal due to the highly protective and restricted bone tissue, where cancerous cells must acquire osteomimetic abilities in order to survive in the bone microenvironmen. ${ }^{7}$ Concerning LNCaP cells, these are dependent on external androgens for growth and, to correlate more closely to the clinical scenario, cells were cultured under an androgen-depleted condition to mimic the system of patients who undergo androgen deprivation therapy (ADT). The CLSM and SEM images of LNCaP were consistent, and helped to understand the metabolic activity results, where the cells underwent morphogenic changes when in 3D, forming tumor-like structures with compact multilayered masses, with high 

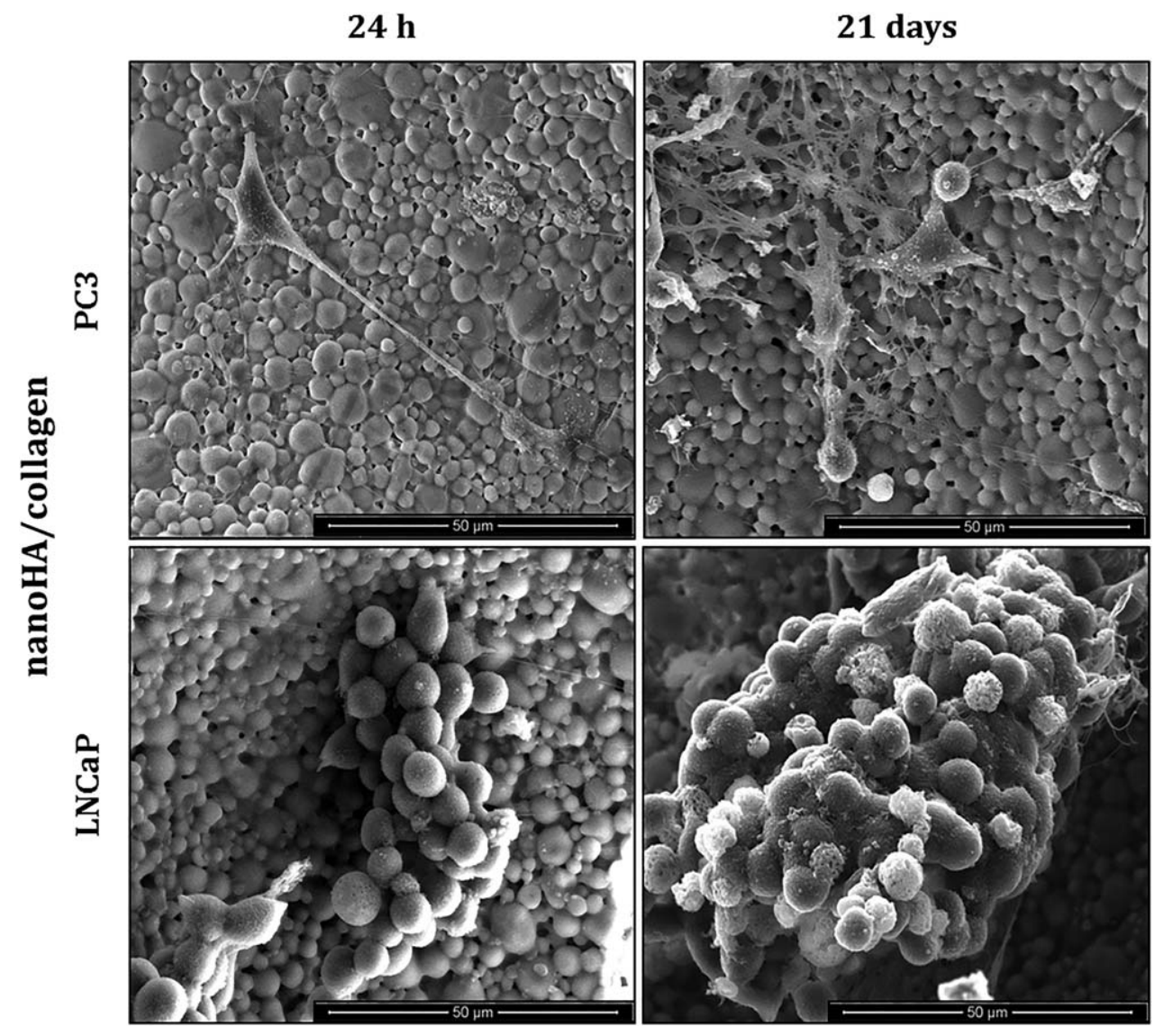

FIGURE 8. SEM micrographs of the nanoHA/collagen cell-seeded scaffolds of PC3 and LNCaP cells after 24 h and 21 days. Top right image displays a region with ECM produced by PC3 cells.

possibility of hypoxic and apoptotic cores. Other research studies have reported a similar cell morphology behavior when in 3D. ${ }^{14,18,28,29,42}$

Regarding the tested SPARC concentration of $10 \mu \mathrm{g} / \mathrm{mL}$, no differences were identified in terms of PCa cell morphology. Yet, the presence of SPARC had a positive influence on cell metabolic activity of LNCaP cells. Particularly, the metabolic activity values decreased nearly $100 \%$ when comparing $4 \mathrm{~h}$ with 21 days of culture for both scaffolds without protein pre-adsorption, whereas both scaffolds with SPARC pre-adsorbed only decreased $70 \%$, suggesting that SPARC plays a role in retaining $\mathrm{LNCaP}$ cells at the latter time points. These results are in accordance with a previous work where the presence of exogenous SPARC contributed to the survival and significant growth of a non-bone metastatic PCa cell line (LNCaP) on bone-like construct. The addition of exogenous SPARC might have compensated for the expected low SPARC expression levels in LNCaP, providing a significant advantage growth on a bone-like biomaterial through regulation of signaling integrins and interaction with ECM components. ${ }^{14}$

Between the three studied cell lines, the MC3T3-E1 was the one presenting the highest colonization level. PC3 was expected to have a colonization level very similar to MC3T3-E1 due to its aggressiveness and its tendency to metastasize into bone tissue. ${ }^{42,43}$ The different extraction sources and different levels of aggressiveness of the two PCa lines, can also explain the very different behavior and adaptability between PC3 and LNCaP. Published studies reported that collagen type I acts as an adhesive substrate for cancer cells and may influence the retention of metastatic cells in the skeleton. ${ }^{44}$ Therefore, a higher metabolic activity in PC3 and LNCaP was expected in the presence of collagen. Nevertheless, the production of fibrillar ECM by PC3 cells was detected at 21 days in the nanoHA/collagen scaffolds.

In brief, the present results suggest that these scaffolds were adequate for adsorption of SPARC and cell culture studies. Moreover, this 3D model may be used as synthetic bone substitute for small bone defects and in extending the knowledge of tumor cell biology, not just for PCa but also for other tumors that similarly metastasize to bone (breast cancer for instance), which may help to advance PCa clinical outcomes.

\section{CONCLUSIONS}

In prostate cancer, the interactions between cancer cells and their microenvironment are fundamental to understand the progression of this pathology. Accordingly, a 3D model for in vitro studies that would approach a tumor microenvironment in bone 
was designed. These scaffolds were capable of providing a 3D support for adhesion and colonization of both MC3T3-E1 and PC3 cells. On the other hand, a different cell behavior was observed with the LNCaP cell line that derives from a non-bone metastatic site, in which cells grew as clusters. Few studies are reported using 3D biomaterials to culture PCa cells, therefore this line of work represents a novel type of study for the understanding of cancer biology. The versatility of these 3D models offers great opportunities to study cancers that metastasize primarily to bone. Hopefully, this will ultimately benefit the development of cancer therapies.

\section{ACKNOWLEDGMENTS}

The authors acknowledge Centro de Investigação do Instituto Português de Oncologia do Porto (IPO-Porto) for kindly providing the prostate cancer cells, Fluidinova S.A. (Maia-Portugal) for the nanoHA (nanoXIM) powder.

\section{REFERENCES}

1. Jemal A, Siegel R, Ward E, Hao Y, Xu J, Murray T, et al. Cancer Statistics, 2008. Cancer J Clin 2008;58:71-96.

2. Li J, Djenaba JA, Soman A, Rim SH, Master VA. Recent trends in prostate cancer incidence by age, cancer stage, and grade, the United States, 2001-2007. Prostate Cancer 2012;2012:8. Article ID 691380, pages, doi:10.1155/2012/691380.

3. De S, Chen J, Narizhneva NV, Heston W, Brainard J, Sage EH, Byzova TV. Molecular pathway for cancer metastasis to bone. J Biol Chem 2003;278:39044.

4. Sturge J, Caley MP, Waxman J. Bone metastasis in prostate cancer: Emerging therapeutic strategies. Nat Rev Clin Oncol 2011; 8:357-368.

5. Yin JJ, Pollock CB, Kelly K. Mechanisms of cancer metastasis to the bone. Cell Res 2005;15:57-62.

6. Framson PE, Sage EH. SPARC and tumor growth: Where the seed meets the soil? J Cell Biochem 2004;92:679-690.

7. Koeneman KS, Yeung F, Chung LWK. Osteomimetic properties of prostate cancer cells: A hypothesis supporting the predilection of prostate cancer metastasis and growth in the bone environment. Prostate 1999;39:246-261.

8. Brekken RA, Sage EH. SPARC, a matricellular protein: At the crossroads of cell-matrix. Matrix Biol 2000;19:569-580.

9. Rivera $L$, Bradshaw $A$, Brekken R. The regulatory function of SPARC in vascular biology. Cell Mol Life Sci 2011;68:3165-3173.

10. Ribeiro N, Sousa SR, Brekken RA, Monteiro FJ. Role of SPARC in bone remodeling and cancer-related bone metastasis. J Cell Biochem 2013;115:17-26.

11. Wong S, Crowley D, Bronson R, Hynes R. Analyses of the role of endogenous SPARC in mouse models of prostate and breast cancer. Clin Exp Metastasis 2008;25:109-118.

12. Jacob K, Webber M, Benayahu D, Kleinman HK. Osteonectin promotes prostate cancer cell migration and invasion: A possible mechanism for metastasis to bone. Cancer Res 1999;59:44534457.

13. Arnold S, Brekken R. SPARC: a matricellular regulator of tumorigenesis. J Cell Commun Signal 2009;3:255-273.

14. Ribeiro N, Costa-Pinheiro P, Henrique R, Gomez-Lazaro M, Pereira MP, Mansur AAP, Mansur HS, Jerónimo C, Sousa SR, Monteiro FJ. Comprehensive analysis of SPARC in prostate carcinogenesis: Development of a 3D nanostructured bone-like model. J Biomed Nanotechnol 2016;12:1667-1678. Vol.

15. Wang $R, X u$ J, Juliette L, Castilleja A, Love J, Sung SY, Zhau HE, Goodwin TJ, Chung LW. Three-dimensional co-culture models to study prostate cancer growth, progression, and metastasis to bone. Semin Cancer Biol 2005;15:353-364.

16. Chu JH, Yu S, Hayward SW, Chan FL. Development of a threedimensional culture model of prostatic epithelial cells and its use for the study of epithelial-mesenchymal transition and inhibition of PI3K pathway in prostate cancer. Prostate 2009;69:428-442.
17. Xu X, Gurski LA, Zhang C, Harrington DA, Farach-Carson MC, Jia $X$. Recreating the tumor microenvironment in a bilayer, hyaluronic acid hydrogel construct for the growth of prostate cancer spheroids. Biomaterials 2012;33:9049-9060.

18. Sieh S, Taubenberger AV, Rizzi SC, Sadowski M, Lehman ML, Rockstroh $A$, et al. Phenotypic characterization of prostate cancer LNCaP cells cultured within a bioengineered microenvironment. PLoS One 2012;7: e40217.

19. Hanahan D, Weinberg RA. Hallmarks of cancer: The next generation. Cell 2011;144:646-674.

20. Teixeira S, Rodriguez MA, Pena P, De Aza AH, De Aza S, Ferraz $\mathrm{MP}$, et al. Physical characterization of hydroxyapatite porous scaffolds for tissue engineering. Mater Sci Eng C 2009;29:1510-1514.

21. Gilles MA, Hudson AQ, Borders CL. Stability of water-soluble carbodiimides in aqueous-solution. Anal Biochem 1990;184:244-248.

22. Wissink MJB, Beernink R, Pieper JS, Poot AA, Engbers GHM, Beugeling $T$, et al. Immobilization of heparin to EDC/NHS-crosslinked collagen. Characterization and in vitro evaluation. Biomaterials 2001;22:151-163.

23. Amaral IF, Sousa S, Neiva I, Marcos-Silva L, Kirkpatrick CJ, Barbosa MA, et al. Kinetics and isotherm of fibronectin adsorption to three-dimensional porous chitosan scaffolds explored by 125I-radiolabelling. Biomaterials 2013;3:e24791.

24. González-García C, Sousa SR, Moratal D, Rico P, SalmerónSánchez M. Effect of nanoscale topography on fibronectin adsorption, focal adhesion size and matrix organisation. Colloids Surf B 2010;77:181-190.

25. Ribeiro N, Sousa SR, Monteiro FJ. Influence of crystallite size of nanophased hydroxyapatite on fibronectin and osteonectin adsorption and on MC3T3-E1 osteoblast adhesion and morphology. J Colloid Interface Sci 2010;351:398-406.

26. Ribeiro CC, Gibson I, Barbosa MA. The uptake of titanium ions by hydroxyapatite particles-Structural changes and possible mechanisms. Biomaterials 2006;27:1749-1761.

27. Chang MC, Tanaka JFT-IR. study for hydroxyapatite/collagen nanocomposite cross-linked by glutaraldehyde. Biomaterials 2002;23: 4811-4818.

28. Sieh S, Lubik AA, Clements JA, Nelson CC, Hutmacher DW. Interactions between human osteoblasts and prostate cancer cells in a novel 3D in vitro model. Organogenesis 2010;6:181-188.

29. Sieh S, Taubenberger AV, Lehman ML, Clements JA, Nelson CC, Hutmacher DW. Paracrine interactions between LNCaP prostate cancer cells and bioengineered bone in $3 D$ in vitro culture reflect molecular changes during bone metastasis. Bone 2014;63:121.

30. Reichert JC, Quent VM, Burke LJ, Stansfield SH, Clements JA, Hutmacher DW. Mineralized human primary osteoblast matrices as a model system to analyse interactions of prostate cancer cells with the bone microenvironment. Biomaterials 2010;31:7928-7936.

31. Marzec E, Pietrucha K. The effect of different methods of crosslinking of collagen on its dielectric properties. Biophys Chem 2008;132:89-96.

32. Kleinman HK, Klebe RJ, Martin GR. Role of collagenous matrices in the adhesion and growth of cells. J Cell Biol 1981;88:473-485.

33. van Wachem PB, van Luyn MJA, Damink LHHO, Dijkstra PJ, Feijen $J$, Nieuwenhuis $P$. Biocompatibility and tissue regenerating capacity of crosslinked dermal sheep collagen. J Biomed Mater Res 1994;28:353-363.

34. Ishaug SL, Crane GM, Miller MJ, Yasko AW, Yaszemski MJ, Mikos AG. Bone formation by three-dimensional stromal osteoblast culture in biodegradable polymer scaffolds. J Biomed Mater Res 1997;36:17-28.

35. Kim B-S, Mooney DJ. Development of biocompatible synthetic extracellular matrices for tissue engineering. Trends Biotechnol 1998;16:224-230.

36. Ho ST, Hutmacher DW. A comparison of micro CT with other techniques used in the characterization of scaffolds. Biomaterials 2006;27:1362-1376.

37. Guda T, Walker JA, Singleton B, Hernandez J, Oh DS, Appleford $M R$, et al. Hydroxyapatite scaffold pore architecture effects in large bone defects in vivo. J Biomater Appl 2013.

38. Sopyan I, Mel M, Ramesh S, Khalid KA. Porous hydroxyapatite for artificial bone applications. Sci Technol Adv Mater 2007;8:116123. 
39. Cunningham E, Dunne N, Clarke S, Walker G, Wilcox R, Unger E, et al. Comparative characterisation of 3D hydroxyapatite scaffolds eveloped via replication of synthetic polymer foams and natural marine sponges. J Tissue Sci Eng 2011;S1:001.

40. Sang L-C, Vinu A, Coppens M-O. General description of the adsorption of proteins at their iso-electric point in nanoporous materials. Langmuir 2011;27:13828-13837.

41. Murphy CM, Haugh MG, O'Brien FJ. The effect of mean pore size on cell attachment, proliferation and migration in collagenglycosaminoglycan scaffolds for bone tissue engineering. Biomaterials 2010;31:461-466.

42. Talukdar S, Mandal M, Hutmacher DW, Russell PJ, Soekmadji C, Kundu SC. Engineered silk fibroin protein 3D matrices for in vitro tumor model. Biomaterials 2011;32:2149-2159.

43. Shariat SF, Lotan Y, Saboorian H, Khoddami SM, Roehrborn CG, Slawin KM, et al. Survivin expression is associated with features of biologically aggressive prostate carcinoma. Cancer 2004;100: 751-757.

44. Kiefer J, Alexander A, Farach-Carson M. Type I collagen-mediated changes in gene expression and function of prostate cancer cells. In: Keller E, Chung LK, editors. The Biology of Skeletal Metastases. Springer; 2004. p. 101-124. 